\title{
N-butanol extracts of Morinda citrifolia suppress advanced glycation end products (AGE)-induced inflammatory reactions in endothelial cells through its anti-oxidative properties
}

Yuji Ishibashi ${ }^{1}$, Takanori Matsui ${ }^{1}$, Fumiyuki Isami ${ }^{2}$, Yumi Abe $^{2}$, Tatsuya Sakaguchi ${ }^{3}$, Yuichiro Higashimoto ${ }^{3}$ and Sho-ichi Yamagishi ${ }^{* *}$

\begin{abstract}
Background: Advanced glycation end products (AGEs), senescent macroprotein derivatives formed during a normal aging process and acceleratedly under diabetic conditions, play a role in atherosclerotic cardiovascular disease. AGEs cause endothelial cell (EC) damage, an initial trigger for atherosclerosis through the interaction with a receptor for AGEs (RAGE). We have previously shown that n-butanol extracts of Morinda citrifolia (noni), a plant belonging to the family Rubiaceae, block the binding of AGEs to RAGE in vitro. In this study, we examined the effects of n-butanol extracts of noni on reactive oxygen species (ROS) generation and inflammatory reactions on AGE-exposed human umbilical vein ECs (HUVECs).
\end{abstract}

Methods: HUVECs were treated with $100 \mu \mathrm{g} / \mathrm{ml}$ AGE-bovine serum albumin (AGE-BSA) or non-glycated BSA in the presence or absence of $670 \mathrm{ng} / \mathrm{ml} \mathrm{n}$-butanol extracts of noni for $4 \mathrm{~h}$. Then ROS generation and inflammatory and gene expression in HUVECs were evaluated by dihydroethidium staining and real-time reverse transcription-polymerase chain reaction analyses, respectively. THP-1 cell adhesion to HUVECs was measured after 2-day incubation of AGE-BSA or BSA in the presence or absence of $670 \mathrm{ng} / \mathrm{ml} \mathrm{n}$-butanol extracts of noni.

Results: N-butanol extracts of noni at $670 \mathrm{ng} / \mathrm{ml}$ significantly inhibited the AGE-induced ROS generation and RAGE, intercellular adhesion molecule-1 and plasminogen activator inhibitor-1 gene expressions in HUVECs. AGEs significantly increased monocytic THP-1 cell adhesion to HUVECs, which was also prevented by $670 \mathrm{ng} / \mathrm{ml}$ n-butanol extracts of noni.

Conclusions: The present study demonstrated for the first time that N-butanol extracts of noni could suppress the AGE-induced inflammatory reactions in HUVECs through its anti-oxidative properties via blocking of the interaction of AGEs with RAGE. Inhibition of the AGE-RAGE axis by n-butanol extracts of noni may be a novel nutraceutical strategy for the treatment of cardiovascular disease.

Keywords: AGEs, RAGE, Oxidative stress, Atherosclerosis

\footnotetext{
* Correspondence: shoichi@med.kurume-u.ac.jp

${ }^{1}$ Department of Pathophysiology and Therapeutics of Diabetic Vascular

Complications, Kurume University School of Medicine, Kurume 830-0011,

Japan

Full list of author information is available at the end of the article
} 


\section{Background}

Reactive derivatives from non-enzymatic reactions between sugars and amino groups of proteins, lipids and nucleic acids form a heterogeneous group of irreversible adducts called "AGEs (advanced glycation end products)" [1-3]. The formation and accumulation of AGEs have been known to progress at a physiological normal aging process and more acceleratedly under diabetic conditions, thereby being involved in the development and progression of atherosclerotic cardiovascular disease [1-14]. Indeed, diabetic apolipoprotein E-deficient mice fed an AGE-restricted diet exhibited less atherosclerotic lesions, which were associated with decreased AGEs, receptor for AGEs (RAGE) and inflammatory cells in the aortic roots [5]. There was a correlation between AGE levels and the degree of atheroma in cholesterol-fed rabbits, whereas treatment with aminoguanidine, an inhibitor of AGE formation decreased plaque formation in the aortae of these animals [6]. Administration of a recombinant soluble form of RAGE consisting of the extracellular AGE-binding domain, has not only suppressed the development of atherosclerosis but also stabilized established atherosclerosis in diabetic apolipoprotein E-null mice [7, 8]. RAGE-deficient mice were found to be resistant to the development of atherosclerosis when they were rendered diabetic [9]. Furthermore, circulating levels of AGEs have also been shown to predict total and cardiovascular disease mortality in both type 1 and type 2 diabetic patients $[10,11]$. These observations suggest that the inhibition of the AGE-RAGE axis is a novel therapeutic target for atherosclerotic cardiovascular disease, espeicially in elderly people or diabetic patients.

We have previously shown that n-butanol extracts of Morinda citrifolia (noni), a plant belonging to the family Rubiaceae, which has been used for centuries by Pacific Islanders as an alternative medicine for various disorders, such as diabetes and arthritis $[15,16]$, block the binding of AGEs to RAGE in vitro [17]. In this study, we examined the effects of n-butanol extracts of noni on reactive oxygen species (ROS) generation and inflammatory reactions on AGE-exposed human umbilical vein endothelial cells (HUVECs).

\section{Methods}

\section{Materials}

Bovine serum albumin (BSA) (essentially fatty acid free and essentially globulin free, lyophilized powder) and D-glyceraldehyde were purchased from Sigma (St. Louis, MO, USA). Ethyl acetate and n-butanol were purchased from Wako Pure Chemical Industries, Ltd. (Osaka, Japan).

\section{Preparation of AGE-BSA}

AGE-modified BSA was prepared as described previously [18]. In brief, BSA (25 $\mathrm{mg} / \mathrm{ml})$ was incubated under sterile conditions with $0.1 \mathrm{M}$ glyceraldehyde in $0.2 \mathrm{M} \mathrm{NaPO}$ buffer (pH 7.4) at $37{ }^{\circ} \mathrm{C}$ for 7 days. Control non-glycated BSA was incubated in the same conditions except for the absence of glyceraldehyde as described previously [18].

\section{Cells}

HUVECs obtained from Lonza Group Ltd. (Basel, Switzerland) were cultured in endothelial basal medium supplemented with $2 \%$ fetal bovine serum, $0.4 \%$ bovine brain extracts, $10 \mathrm{ng} / \mathrm{ml}$ human epidermal growth factor and $1 \mu \mathrm{g} / \mathrm{ml}$ hydrocortisone according to the manufacturer's recommendation. AGE or non-glycated BSA treatment was carried out in a medium lacking epidermal growth factor and hydrocortisone. Cells at passage 4-11 were used for the present experiments. According to the certificate of analysis by Lonza Group Ltd., HUVECs were pooled from Caucasian newborn babies. Isolated cells were identified as HUVECs because cells expressed CD31/105, von Williebrand Factor VIII, and were positive for acetyated low-density lipoprotein uptake. All cells were negative for mycoplasma.

\section{Preparation of $\mathbf{n}$-butanol extracts of noni}

Morinda citrifolia fruits were collected in French Polynesia during 2004-2006 and identified by botanists at Tropical Resources, Inc. (Provo, UT, USA) where voucher specimens were deposited (Part No. 119107, Lot Code 52488, Batch \# 23401). The fruits were separated into flesh and seeds by hand. The flesh was freezedried, extracted with 50\% ethanol, and then the extracts were further extracted with ethyl acetate and n-butanol several times as described previously [19].

\section{Dihydroethidium (DHE) staining}

HUVECs were treated with $100 \mu \mathrm{g} / \mathrm{ml}$ AGE-BSA or nonglycated BSA in the presence or absence of $670 \mathrm{ng} / \mathrm{ml}$ n-butanol extracts of noni for $4 \mathrm{~h}$. Then the cells were incubated with phenol red free Dulbecco's Modified Eagle Medium containing $3 \mu \mathrm{M}$ DHE (Molecular Probes Inc., Eugene, OR, USA). After $15 \mathrm{~min}$, ROS generation was evaluated by intensity of DHE staining as described previously [20]. Intensity of DHE staining in five different field of each sample was analyzed by microcomputer-assisted image J.

\section{Real-time reverse transcription-polymerase chain reactions (RT-PCR)}

HUVECs were treated with $100 \mu \mathrm{g} / \mathrm{ml}$ AGE-BSA or non-glycated BSA in the presence or absence of $670 \mathrm{ng} /$ $\mathrm{ml}$ n-butanol extracts of noni for $4 \mathrm{~h}$. Then total RNA was extracted with RNAqueous-4PCR kit, and quantitative real-time RT-PCR was performed using Assay-onDemand and TaqMan 5 fluorogenic nuclease chemistry (Applied Biosystems, Foster city, CA, USA) as described 
previously [20]. IDs of primers for human RAGE, intercellular adhesion molecule-1 (ICAM-1), plasminogen activator inhibitor-1 (PAI-1), $\beta$-actin, and $18 \mathrm{~S}$ gene were Hs00542592_g1, Hs00164932_m1, Hs01126606_m1, Hs0 1060665_g1, and Hs03003631_g1, respectively.

\section{Assay of THP-1 cell adhesion to HUVECs}

Human THP-1 monocytic leukemia cells were purchased from American Type Culture Collection (Manassas, VA, USA) and labeled with $3 \mu \mathrm{M}$ BCECFAM (Dojindo, Kumamoto, Japan) as described previously [21]. HUVECs were treated with $100 \mu \mathrm{g} / \mathrm{ml}$ AGE-BSA or non-glycated BSA in the presence or absence of $670 \mathrm{ng} / \mathrm{ml} \mathrm{n}$-butanol extracts of noni for $24 \mathrm{~h}$ and then incubated with BCECF-AM-labeled THP-1 cells for $4 \mathrm{~h}$. After the incubation, non-adherent THP-1 cells were removed, and fluorescent intensities of the adherent THP-1 cells were measured as described previously [21].

\section{Statistical analysis}

All values were presented as mean \pm standard error. One-way ANOVA followed by Student's $t$-test was performed for statistical comparisons; $p<0.05$ was considered significant. All statistical analyses were performed using the R version 3.2.5 (Copenhagen Business School, Frederiksberg, Denmark).

\section{Results}

Effects of noni extracts on ROS generation

We first examined the effects of $n$-butanol extracts of noni on ROS generation in HUVECs. As shown in Fig. 1, AGEs significantly increased ROS generation in HUVECs, which was prevented by $670 \mathrm{ng} / \mathrm{ml} \mathrm{n}$-butanol extracts of noni. Noni extracts did not affect ROS generation in non-glycated BSA-exposed HUVECs.

\section{Effects of noni extracts on RAGE, ICAM-1 and PAI-1 gene expressions}

We next investigated the effects of noni extracts on inflammatory reactions in HUVECs. AGEs up-regulated RAGE mRNA levels in HUVECs, which was associated with the increases in ICAM-1 and PAI-1 gene expressions (Fig. 2). N-butanol extracts of noni at $670 \mathrm{ng} / \mathrm{ml}$ significantly blocked the AGE-induced gene expressions of RAGE, ICAM- 1 and PAI-1 in HUVECs. Noni extracts did not affect these mRNA levels in non-glycated BSA-exposed HUVECs.

Effects of noni extracts on THP-1 cell adhesion to HUVECs We further studied the effects of noni extracts on THP-1 cell adhesion to HUVECs. As shown in Fig. 3, $670 \mathrm{ng} / \mathrm{ml}$ n-butanol extracts of noni significantly prevented the increase in THP-1 cell adhesion to AGE-exposed HUVECs. Noni extracts did not affect THP-1 cell adhesion to non-glycated BSA-exposed HUVECs.
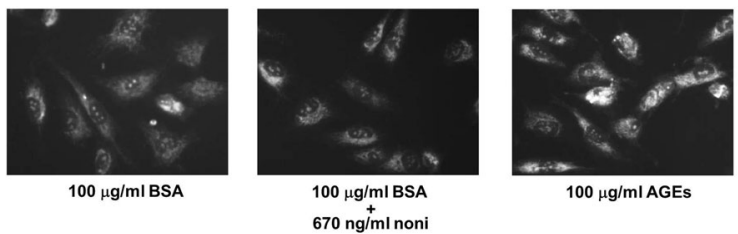

$100 \mu \mathrm{g} / \mathrm{ml}$ AGEs

$670 \mathrm{ng} / \mathrm{m}$ I noni

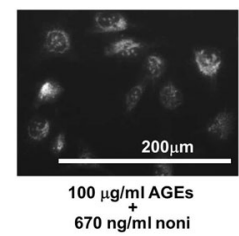

$670 \mathrm{ng} / \mathrm{ml}$ noni

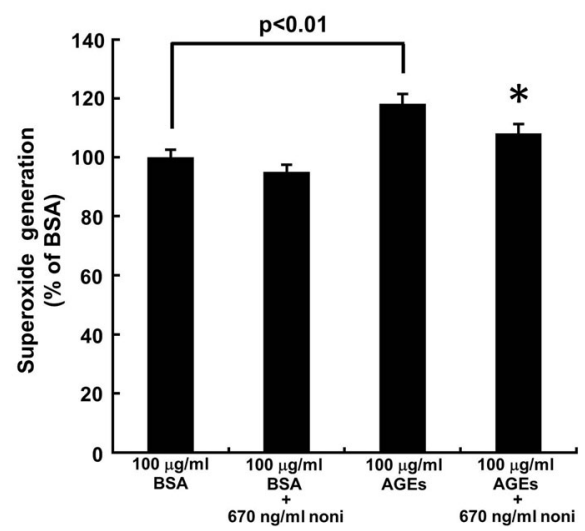

Fig. 1 Effects of noni extracts on ROS generation in AGE-exposed HUVECs. HUVECs were treated with $100 \mu \mathrm{gg} / \mathrm{ml}$ AGE-BSA or non-glycated BSA in the presence or absence of $670 \mathrm{ng} / \mathrm{ml} \mathrm{n}$-butanol extracts of noni for $4 \mathrm{~h}$. Then superoxide generation was evaluated by intensity of DHE staining. Upper panels show the representative photos of DHE stainings. Lower panel shows the quantitative data. $N=3$ per group. ${ }^{*}, p<0.05$ compared to the value with AGEs alone 
a

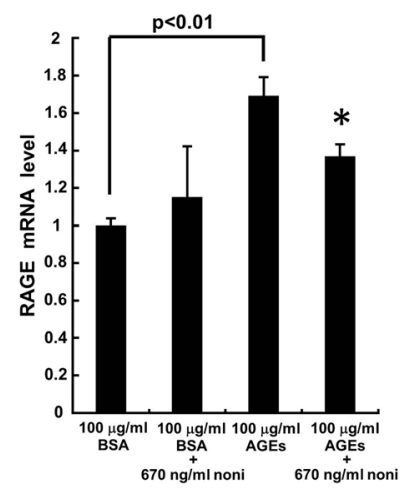

b

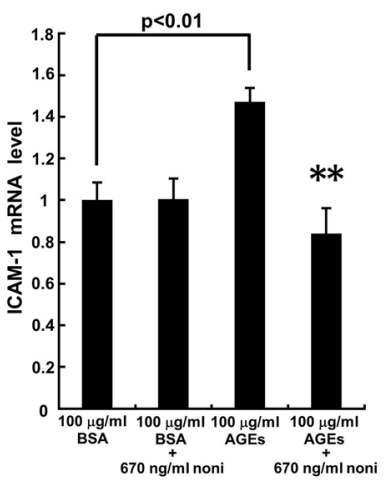

C

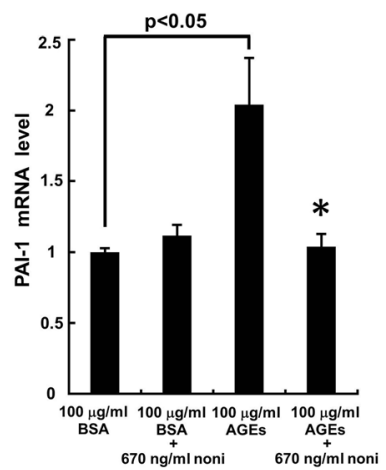

Fig. 2 Effects of noni extracts on RAGE (a), ICAM-1 (b), and PAI-1 (c) mRNA levels in AGE-exposed HUVECs. HUVECs were treated with $100 \mu \mathrm{g} / \mathrm{ml}$ AGE-BSA or non-glycated BSA in the presence or absence of $670 \mathrm{ng} / \mathrm{ml} \mathrm{n}$-butanol extracts of noni for $4 \mathrm{~h}$. Then total RNAs were transcribed and amplified by real-time PCR. Data were normalized by the intensity of $\beta$-actin (a) or $18 \mathrm{~S}$ mRNA-derived signals $(\mathbf{b}$ and $\mathbf{c}$ ) and then related to the value obtained with non-glycated BSA treatment alone. a $N=4$ per group. $\mathbf{b}$ and $\mathbf{c} N=8$ per group. ${ }^{*}$ and ${ }^{* *}, p<0.05$ and $p<0.01$ compared to the value with AGEs alone, respectively

\section{Discussion}

There is an accumulating body of experimental and epidemiological evidence that atherosclerosis is intrinsically an inflammatory disease and that endothelial cell damage and dysfunction are an initial event that leads to the development of atherosclerotic cardiovascular disease [22-24]. Furthermore, recent understandings of the disease process have also revealed that AGEs and RAGE interaction could evoke oxidative stress generation and

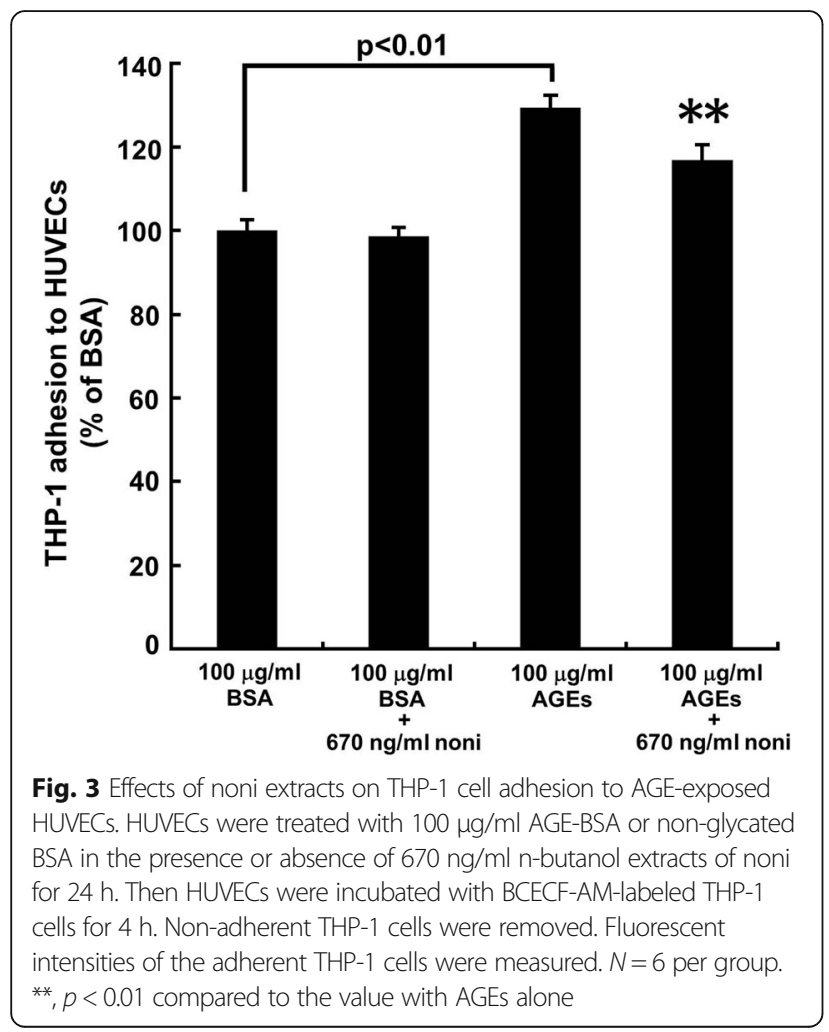

cause inflammatory reactions, thus contributing to the increased risk for cardiovascular disease in elderly patients, especially poorly controlled diabetes $[4-9,25$, 26]. We have very recently found that n-butanol extracts of noni could prevent the interaction of AGEs with RAGE in vitro by binding RAGE with a dissociation constant of $640 \mu \mathrm{g} / \mathrm{ml}$ and a half maximal inhibitory concentration of $200 \mathrm{ng} / \mathrm{ml}$ [17]. Therefore, we examined here the effects of n-butanol extracts of noni on the AGE-RAGE axis in HUVECs.

In this study, we found for the first time that n-butanol extracts of noni significantly inhibited the AGEinduced ROS generation, RAGE, ICAM-1 and PAI-1 gene expressions in HUVECs, which were associated with attenuation of THP-1 cell adhesion to AGE-exposed HUVECs. We have previously shown that antibody or antisense DNA raised against RAGE completely inhibits the AGE-evoked ROS generation in endothelial cells, while an anti-oxidant $N$-acetylcysteine or RAGE antibody itself blocks up-regulation of RAGE mRNA levels in AGE-exposed endothelial cells [21, 27, 28]. So our present study suggests that $n$-butanol extracts of noni may inhibit the deleterious effects of AGEs by breaking the vicious cycle between ROS generation and RAGE overexpression in HUVECs.

ICAM-1 stimulates the recruitment and firm adhesion of inflammatory cells to endothelial cells, which could promote inflammatory reactions in atherosclerosis [29]. Furthermore, attenuated fibrinolytic activity by increased PAI-1 levels is associated with the increased risk for atherothrombosis and cardiovascular disease in diabetic patients [30]. Given that AGEs could induce ICAM-1 and PAI-1 gene expressions in HUVECs via ROS generation through the interaction with RAGE [21, 31], blockade of the AGE-RAGE interaction by n-butanol extracts 
of noni may be a central mechanism by which they could protect against AGE-induced endothelial cell injury, thus becoming a therapeutic target for atherosclerotic cardiovascular disease. Iridoids are found in various types of medicinal plants, including noni, have been reported to block the inflammatory reactions in AGE-exposed mesangial cells and kidneys of diabetic mice [32,33]. It would be interesting to examine whether iridoids could actually inhibit the binding of AGEs to RAGE in vitro.

\section{Limitations}

Although the composition of noni fruits has been extensively studied and there are a lot of data available on how to analyze the bioactive compounds [15-17, 19], the active substance has not been fully characterized in the present study. Further experiments using high performance liquid chromatography would be helpful to address the issue.

In this study, freeze-dried flesh of Morinda citrifolia was extracted first with $50 \%$ ethanol, and then with ethyl acetate and n-butanol several times. The reason why the native ethanol extracts were not included in this study was that they were inactive; their binding affinity to RAGE was less than one-sixth of those of n-butanol extracts (data not shown). Furthermore, n-butanol extracts alone did not affect superoxide generation or inflammatory reactions in BSA-exposed HUVECs (Figs. 2 and 3). So it is unlikely that the solvents exerted toxic effects on HUVECs. However, the relevance of n-butanol extracts as a potential therapeutic agent in diabetic vascular complications remains unclear.

We used freeze-dried samples after more than 10 years of storage in the present experiments. However, just after the collection during 2004-2006, the fruits were freeze-dried and stored in dark place at $4{ }^{\circ} \mathrm{C}$. Our previous and present studies have suggested that the butanol extracts of freeze-dried and stored samples are bioactive because they not only inhibited the binding of AGEs to RAGE [17], but also suppressed the harmful effects of AGEs on HUVECs. It would be interesting to compare the bioactivity of fresh samples with that of stored samples in HUVECs.

In the present study, the effects of AGEs on ICAM-1 and PAI-1 mRNA levels were much stronger than on RAGE mRNA levels. Although AGEs have been shown to evoke the inflammatory reactions in HUVECs via RAGE interaction $[21,31]$, the time-response curves of gene expressions may differ.

\section{Conclusions}

The present study suggests that n-butanol extracts of noni may inhibit inflammatory reactions in AGEexposed HUVECs through its anti-oxidative properties. Since we have found that circulating levels of AGEs are associated with vascular inflammation and endothelial dysfunction in humans [34, 35], blockade by noni extracts of the interaction of AGE with RAGE may be a novel therapeutic strategy for atherosclerotic cardiovascular disease.

\section{Abbreviations \\ AGEs: Advanced glycation end products; BSA: Bovine serum albumin; DHE: Dihydroethidium; HUVECs: Human umbilical vein endothelial cells; ICAM-1: Intercellular adhesion molecule-1; PAI-1: Plasminogen activator inhibitor-1; RAGE: Receptor for AGEs; ROS: Reactive oxygen species; RT-PCR: Real-time reverse transcription-polymerase chain reactions}

\section{Acknowledgments}

None.

Funding

None.

Availability of data and materials

Data are all contained within the article.

Authors' contributions

YI, TM, FI, YA, TS, and YH acquired and interpreted data. SY mainly contributed to the present study, conceptualized and designed the study, acquired, analyzed, and interpreted data, and drafted the manuscript, and took responsibility for the integrity of the data and the accuracy of the data analysis. All authors read and approved the final manuscript.

\section{Competing interests}

FI and YA are employees of Morinda Worldwide Inc., Japan. SY received honoraria such as lecture fees from Morinda Worldwide Inc., Japan.

\section{Consent for publication}

All authors gave their consent for the publication of the manuscript and for Sho-ichi Yamagishi to be a corresponding author.

Ethics approval and consent to participate

Not applicable.

\section{Author details}

${ }^{1}$ Department of Pathophysiology and Therapeutics of Diabetic Vascular Complications, Kurume University School of Medicine, Kurume 830-0011, Japan. ${ }^{2}$ Morinda Worldwide Inc., Tokyo 160-0023, Japan. ${ }^{3}$ Department of Chemistry, Kurume University School of Medicine, Kurume 830-0011, Japan.

Received: 28 October 2016 Accepted: 21 February 2017

Published online: 04 March 2017

\section{References}

1. Cerami A, Vlassara $H$, Brownlee M. Role of nonenzymatic glycosylation in atherogenesis. J Cell Biochem. 1986;30:111-20.

2. Stitt AW, Bucala R, Vlassara $H$. Atherogenesis and advanced glycation: promotion, progression, and prevention. Ann NY Acad Sci. 1997;811:115-27.

3. Monnier VM, Sell DR, Genuth S. Glycation products as markers and predictors of the progression of diabetic complications. Ann NY Acad Sci. 2005;1043:567-81.

4. López-Díez R, Shekhtman A, Ramasamy R, Schmidt AM. Cellular mechanisms and consequences of glycation in atherosclerosis and obesity, Biochim Biophys Acta. 2016;doi:10.1016/j.bbadis.2016.05.005.

5. Lin RY, Choudhury RP, Cai W, Lu M, Fallon JT, Fisher EA, Vlassara H. Dietary glycotoxins promote diabetic atherosclerosis in apolipoprotein E-deficient mice. Atherosclerosis. 2003;168:213-20.

6. Panagiotopoulos S, O'Brien RC, Bucala R, Cooper ME, Jerums G. Aminoguanidine has an anti-atherogenic effect in the cholesterol-fed rabbit. Atherosclerosis. 1998;136:125-31.

7. Park L, Raman KG, Lee KJ, Lu Y, Ferran Jr LJ, Chow WS, Stern D, Schmidt AM. Suppression of accelerated diabetic atherosclerosis by the soluble receptor for advanced glycation endproducts. Nat Med. 1998;4:1025-31. 
8. Bucciarelli LG, Wendt T, Qu W, Lu Y, Lalla E, Rong LL, Goova MT, Moser B, Kislinger T, Lee DC, Kashyap Y, Stern DM, Schmidt AM. RAGE blockade stabilizes established atherosclerosis in diabetic apolipoprotein E-null mice. Circulation. 2002;106:2827-35.

9. Soro-Paavonen A, Watson AM, Li J, Paavonen K, Koitka A, Calkin AC, Barit D, Coughlan MT, Drew BG, Lancaster GI, Thomas M, Forbes JM, Nawroth PP, Bierhaus A, Cooper ME, Jandeleit-Dahm KA. Receptor for advanced glycation end products (RAGE) deficiency attenuates the development of atherosclerosis in diabetes. Diabetes. 2008;57:2461-9.

10. Nin JW, Jorsal A, Ferreira I, Schalkwijk CG, Prins MH, Parving HH, Tarnow L, Rossing P, Stehouwer CD. Higher plasma levels of advanced glycation end products are associated with incident cardiovascular disease and all-cause mortality in type 1 diabetes: a 12-year follow-up study. Diabetes Care. 2011;34:442-7.

11. Kilhovd BK, Juutilainen A, Lehto S, Rönnemaa T, Torjesen PA, Hanssen KF, Laakso M. Increased serum levels of advanced glycation endproducts predict total, cardiovascular and coronary mortality in women with type 2 diabetes: a population-based 18 year follow-up study. Diabetologia. 1997:50:1409-17.

12. Yamagishi S. Potential clinical utility of advanced glycation end product cross-link breakers in age- and diabetes-associated disorders. Rejuvenation Res. 2012;15:564-72.

13. Yamagishi S, Fukami K, Matsui T. Evaluation of tissue accumulation levels of advanced glycation end products by skin autofluorescence: a novel marker of vascular complications in high-risk patients for cardiovascular disease. Int J Cardiol. 2015;185:263-8.

14. Yamagishi $S$, Matsui T. Soluble form of a receptor for advanced glycation end products (SRAGE) as a biomarker. Front Biosci (Elite Ed). 2010;2:1184-95.

15. Nerurkar PV, Hwang PW, Saksa E. Anti-diabetic potential of Noni: the Yin and the Yang. Molecules. 2015;20:17684-719.

16. Brown AC. Anticancer activity of Morinda citrifolia (Noni) fruit: a review. Phytother Resl. 2012;26:1427-40.

17. Yamagishi S, Matsui T, Ishibashi, Isami F, Abe Y, Sakaguchi T, Higashimoto Y. Phytochemicals against advanced glcation end products (AGEs) and the receptor system. Curr Pharm Des. 2016 (in press).

18. Yamagishi S, Nakamura K, Matsui T, Inagaki Y, Takenaka K, Jinnouchi Y, Yoshida Y, Matsuura T, Narama I, Motomiya Y, Takeuchi M, Inoue H, Yoshimura A, Bucala R, Imaizumi T. Pigment epithelium-derived factor inhibits advanced glycation end product-induced retinal vascular hyperpermeability by blocking reactive oxygen species-mediated vascular endothelial growth factor expression. J Biol Chem. 2006;281:20213-20.

19. Masuda M, Murata K, Fukuhama A, Naruto S, Fujita T, Uwaya A, Isami F, Matsuda H. Inhibitory effect of constituents of Morinda citrifolia seed on elastase and tyrosinase. J Nat Med. 2009;63:267-73.

20. Ishibashi Y, Matsui T, Ueda S, Fukami K, Yamagishi S. Advanced glycation end products potentiate citrated plasma-evoked oxidative and inflammatory reactions in endothelial cells by up-regulating proteaseactivated receptor-1 expression. Cardiovasc Diabetol. 2014;13:60

21. Matsui T, Nakamura N, Ojima A, Nishino Y, Yamagishi SI. Sulforaphane reduces advanced glycation end products (AGEs)-induced inflammation in endothelial cells and rat aorta. Nutr Metab Cardiovasc Dis. 2016;26:797-807.

22. Lamon BD, Hajjar DP. Inflammation at the molecular interface of atherogenesis: an anthropological journey. Am J Pathol. 2008;173:1253-64.

23. Corte VD, Tuttolomondo A, Pecoraro R, Pinto A. Inflammation, endothelial dysfunction and arterial stiffness as therapeutic targets in cardiovascular medicine. Curr Pharm Des. 2016 (in press).

24. Gimbrone Jr MA, García-Cardeña G. Endothelial cell dysfunction and the pathobiology of atherosclerosis. Circ Res. 2016;118:620-36.

25. Yamagishi S, Imaizumi T. Diabetic vascular complications: pathophysiology, biochemical basis and potential therapeutic strategy. Curr Pharm Des. 2005;11:2279-99.

26. Yamagishi S. Role of advanced glycation end products (AGEs) and receptor for AGEs (RAGE) in vascular damage in diabetes. Exp Gerontol. 2011;46:217-24.

27. Ojima A, Matsui T, Maeda S, Takeuchi M, Yamagishi S. Glucose-dependent insulinotropic polypeptide (GIP) inhibits signaling pathways of advanced glycation end products (AGEs) in endothelial cells via its antioxidative properties. Horm Metab Res. 2012;44:501-5.

28. Ando R, Ueda S, Yamagishi S, Miyazaki H, Kaida Y, Kaifu K, Yokoro M, Nakayama Y, Obara N, Fukami K, Takeuchi M, Okuda S. Involvement of advanced glycation end product-induced asymmetric dimethylarginine generation in endothelial cells. Diab Vasc Dis Res. 2013;10:436-41.
29. Lawson C, Wolf S. ICAM-1 signaling in endothelial cells. Pharmacol Rep. 2009;61:22-32.

30. Takenaka K, Yamagishi S, Matsui T, Nakamura K, Imaizumi T. Role of advanced glycation end products (AGEs) in thrombogenic abnormalities in diabetes. Curr Neurovasc Res. 2006;3:73-7.

31. Matsui T, Nishino Y, Takeuchi M, Yamagishi S. Vildagliptin blocks vascular injury in thoracic aorta of diabetic rats by suppressing advanced glycation end product-receptor axis. Pharmacol Res. 2011;63:383-8.

32. Xu H, Shen J, Liu H, Shi Y, Li L, Wei M. Morroniside and loganin extracted from Cornus officinalis have protective effects on rat mesangial cell proliferation exposed to advanced glycation end products by preventing oxidative stress. Can J Physiol Pharmacol. 2006;84:1267-73.

33. Yokozawa T, Kang KS, Park CH, Noh JS, Yamabe N, Shibahara N, Tanaka T. Bioactive constituents of Corni Fructus: the therapeutic use of morroniside, loganin, and 7-O-galloyl-D-sedoheptulose as renoprotective agents in type 2 diabetes. Drug Discov Ther. 2010;4:223-34.

34. Kajikawa M, Nakashima A, Fujimura N, Maruhashi T, Iwamoto Y, Iwamoto A, Matsumoto T, Oda N, Hidaka T, Kihara Y, Chayama K, Goto C, Aibara Y, Noma K, Takeuchi M, Matsui T, Yamagishi S, Higashi Y. Ratio of serum levels of AGEs to soluble form of RAGE is a predictor of endothelial function. Diabetes Care. 2015;38:119-25.

35. Tahara N, Yamagishi S, Takeuchi M, Honda A, Tahara A, Nitta Y, Kodama N, Mizoguchi M, Kaida H, Ishibashi M, Hayabuchi N, Matsui T, Imaizumi T. Positive association between serum level of glyceraldehyde-derived advanced glycation end products and vascular inflammation evaluated by [(18)F]fluorodeoxyglucose positron emission tomography. Diabetes Care. 2012;35:2618-25.

\section{Submit your next manuscript to BioMed Central and we will help you at every step:}

- We accept pre-submission inquiries

- Our selector tool helps you to find the most relevant journal

- We provide round the clock customer support

- Convenient online submission

- Thorough peer review

- Inclusion in PubMed and all major indexing services

- Maximum visibility for your research

Submit your manuscript at www.biomedcentral.com/submit
Biomed Central 